\title{
SPECTROSCOPY OF DEFECTS IN NEUTRON IRRADIATED AMMONO-THERMAL GaN BY COMBINING PHOTOIONIZATION, PHOTOLUMINESCENCE AND POSITRON ANNIHILATION TECHNIQUES
}

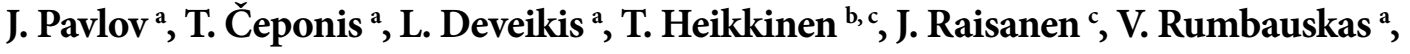 \\ G. Tamulaitis ${ }^{\text {a }}$, F. Tuomisto ${ }^{\text {b,c, d }}$, and E. Gaubas ${ }^{\text {a }}$ \\ ${ }^{a}$ Institute of Photonics and Nanotechnology, Vilnius University, Sauletekio 3, 10257 Vilnius, Lithuania \\ ${ }^{\mathrm{b}}$ Department of Applied Physics, Aalto University, 00076 Aalto Espoo, Finland \\ ${ }^{c}$ Department of Physics, University of Helsinki, 00014 Helsinki, Finland \\ ${ }^{\mathrm{d}}$ Helsinki Institute of Physics, University of Helsinki, 00014 Helsinki, Finland \\ Email: jevgenij.pavlov@tmi.vu.lt
}

Received 11 September 2019; accepted 30 September 2019

\begin{abstract}
In this work, pulsed photoionization as well as photoluminescence and positron annihilation spectroscopy were combined to detect different species of defects. The GaN crystals, grown by the ammono-thermal method, doped with $\mathrm{Mn}$ as well as $\mathrm{Mg}$ impurities and irradiated with different fluences of reactor neutrons, were examined to clarify the role of the technological and radiation defects. The evolution of the prevailing photoactive centres was examined by pulsed photoionization spectroscopy. Positron annihilation spectroscopy was applied to reveal vacancy-type defects.
\end{abstract}

Keywords: pulsed photoionization spectroscopy, photoluminescence, positron annihilation spectroscopy, GaN, defects

\section{Introduction}

$\mathrm{GaN}$ material and its alloys with aluminium have become widely used in fabrication of devices for biological, chemical and radiation sensing [1, 2]. Modern technology grown GaN is particularly interesting for production of radiation tolerant detectors capable of operating in extremely harsh radiation environments. The high luminosity large hadron collider (HL-LHC) will reach fluxes from 5 to 7 of the nominal LHC luminosity [3] and the future circular collider (FCC) is anticipated to reach particle energy up to $100 \mathrm{TeV}[4,5]$. Thereby, the HL-LHC and FCC detectors should withstand the extremely high fluences up to $10^{17} \mathrm{~cm}^{-2}$. Therefore, much effort has been made in search of modern materials for detectors to be used in such conditions for a long time [6]. GaN-based detectors are beneficial due to their capability to generate both the electrical and optical signals. The GaN-based detectors raise technical interest in development of the double-purpose devices capable to operate both as scintillating and charge collecting detectors for tracking of high-energy particles [7-10]. The depth and lateral homogeneity of the sensor structures are therefore necessary to get the linear response of the detector [11]. Moreover, thick sensor structures which satisfy the requirement of bulk uniformity are required to detect events of the relatively small interaction cross-sections. This situation appears in the detection of strongly penetrating radiations. As a result of irradiation, the displacement damage occurs. Then, the lattice atoms are knocked out of their sites creating thereby vacancies and interstitials [12]. Clusters of radiation defects acting as carrier traps affect the opto-electronic characteristics of the devices, reducing the luminescence intensity and efficiency 
of charge collection, increasing the leakage current and thereby changing the detector response [13, 14 .

The GaN single-crystals (even grown by advanced technologies) contain a lot of technological defects yet. Therefore, a trade-off should be found in choice of the GaN growth technology to have a cheap, fast way to devise rather thick radiation sensors, capable of generating double responses. MOCVD GaN epilayers usually have large densities of dislocations, which lead to a fairly high leakage current. The lattice mismatch between the substrate (sapphire, $\mathrm{Si}$ or $\mathrm{SiC}$ ) and $\mathrm{GaN}$ causes stress wafer bowing. This determines the dislocation density not less than $10^{9} \mathrm{~cm}^{-2}$ [15]. Especially, screw dislocations strongly affect the electrical properties of the electronic devices [16]. There exists the epitaxial-lateral-overgrowth (ELO) technology, which allows making of $\mathrm{GaN}$ layers relatively clean from dislocations. However, this technology excludes growth of thick single crystals [17]. The most promising $\mathrm{GaN}$ growth technologies are hydride vapour phase epitaxy (HVPE) and ammono-thermal (AT) method in production of the double-response detectors [18, 49]. The dislocation density less than $10^{6} \mathrm{~cm}^{-2}$ can be reached by the HVPE method. Even lower dislocation densities $\leq 10^{5} \mathrm{~cm}^{-2}$ are achievable by employing the AT technology.

In this study, the AT GaN crystals doped with various impurities and irradiated with different fluences of neutrons were examined to clarify the role of the technological and radiation defects. $\mathrm{Mg}$ impurities are widely exploited in formation of modern devices having specific electrical characteristics [20, 21]. Moreover, Mg impurities serve as the main dopants in formation of the p-type conductivity GaN. Other dopants, namely Mn, may act as the compensating centres for unintentionally induced donor-type defects and fast carrier traps, and that can also be used to obtain semi-insulating or highly resistive material. By manipulating the ratio between the dopant density and the concentration of radiation defects, it is possible to increase the radiation resistance of the sensors. In this work, the evolution of the pulsed photoionization (PPIS), scintillation (pulsed photoluminescence - PPL) and positron annihilation (PAS) [22-25] spectroscopy means have been combined to reveal the prevailing defects of different species and scintillation efficiency with neutron irradiation fluence. The contactless PPIS is beneficial in discovery of photoactive centres. PAS is a powerful method for detecting vacancy-type defects [23].

\section{Samples}

The bulk GaN crystals were grown by the ammono-thermal method [26] at Ammono Company (Poland) [27]. The GaN samples were doped with $\mathrm{Mg}$ and $\mathrm{Mn}$ of concentrations $1 \times 10^{18} \mathrm{~cm}^{-3}$ and $10^{19} \mathrm{~cm}^{-3}$, respectively. The thickness of freestanding AT GaN samples was $400-450 \mu \mathrm{m}$. The AT GaN crystals contained the dislocation density less than $10^{5} \mathrm{~cm}^{-2}$ [28, 29]. In order to emulate the evolution of particle detector functionality during experiments at the LHC, it is preferable to use the reactor neutron irradiation, since homogeneous damage thereby can easily be achieved. The $1 \mathrm{MeV}$ neutron equivalent of radiation damage, caused by the non-ionizing energy loss (NIEL), is widely used for the estimation of the effective fluence, because the NIEL damage becomes then similar under irradiations with different type particles [30]. The AT GaN samples were irradiated by a nuclear reactor at the Jožef Stefan Insitute (Ljubljana) TRIGA reactor [31]. Fast neutrons with the energy peak at $1 \mathrm{MeV}$ and of $7.5 \times 10^{12} \mathrm{n} /\left(\mathrm{cm}^{2} \mathrm{~s}\right)$ flux act as the main generator in defect formation.

\section{Spectroscopy techniques}

\subsection{Pulsed photoionization spectroscopy}

A few results on neutron-irradiated AT GaN materials and the spectral data of the prevailing defects have been reported in our previous publications [32, 33]. In this work, the evolution of the PPI [34] spectra with neutron fluence in a range of $10^{12}-5 \times 10^{16} \mathrm{n} / \mathrm{cm}^{2}$ has been studied in more detail. The pulsed response is recorded using microwave probed photoconductivity transients (MW-PC). The peak MW-PC values were determined within the MW-PC transients to estimate the excess carrier density generated by photoionization processes. These values represent a step-like photoionization spectrum. The relaxation shape and duration of the MW-PC transients represent the carrier lifetime and trap filling/emptying processes within later carrier decay stages. The definite steps of photoionization spectra commonly 
correlate with the changes of the carrier recombination lifetimes, and this allows one to additionally control the filling state of the photoactive centres. The PPIS is preferable for recording of the PC signals, as it is operational in a contactless mode at room temperature and excludes contactrelated effects. In this work tuneable wavelength (in a range of 210 to $2300 \mathrm{~nm}$ ) nanosecond (4 ns) light pulses are generated by an OPO instrument Ekspla NT342B. The sample was placed on the slitantenna of $21 \mathrm{GHz}$ microwave (MW) system and excited by a laser beam. The MW-PC transients were recorded by a $2 \mathrm{GHz}$ oscilloscope LeCroy Wave Runner $620 \mathrm{Zi}$ on a $50 \Omega$ load resistor connected in series with an MW detector.

Photoionization or photo-neutralization of deep levels is characterized by photoionization cross-sections. Spectral changes of the photoionization cross-section $\sigma(h v)$ can be described by the Kopylov-Pikhtin model [35]:

$$
\sigma(h v)=M_{i k}^{2} \int_{0}^{\infty} \frac{\exp \left[-\left(E+E_{d}-h v\right)^{2} / \Gamma^{2}\right] \sqrt{E} \mathrm{~d} E}{h v\left(E+E_{d}\right)^{2}} .
$$

Here $E_{d}$ is the photo-activation energy, $\Gamma$ is the broadening factor, which determines electronphonon coupling, and $M_{i k}$ is the matrix element of a dipole transition from the initial ( $i$ ) (trap level) to the final ( $k$ ) (continuum) state. The broadening factor depends on the ground and excited state vibrational frequencies and Franck-Condon shift [36]. In PPI spectra fitting, the $E_{d}$ and $\Gamma$ were varied as the free parameters to get the best fit estimated by the nonlinear least squares method for experimental spectra. Changes of the absorption coefficient $\alpha(h v)$ for $h v$ energy photons due to photoionization of trapped carriers can then be described by

$$
\alpha(h v)=\sigma(h v) n_{d 0} .
$$

Here $n_{d 0}$ is the concentration of the trapped carriers. The density of the photoemitted carriers, registered by an MW probe, comes from illumination by a light pulse of the surface density of the incident photons

$$
n_{d}^{*}=\sigma(n v) n_{d 0} F(h v),
$$

where $n_{d}{ }_{d}$ is the density of the photoemitted carriers and $F(h v)$ is the fixed surface density of the incident photons of varied energy $h v$.

\subsection{Pulsed scintillation spectroscopy}

The scintillation characteristics have been examined by recording of the UV laser-induced pulsed photoluminescence spectra (PPL) under the experimental conditions close to those of the PPIS measurements. An ultraviolet (UV) laser STA-3H emitting $351 \mathrm{~nm}$ light pulses of 400 ps was employed for the excitation of photoluminescence (PL). A PL response was filtered from a laser beam (using an interference 100\% mirror at laser wavelength), collected into a UV adjusted fiberscope and transmitted to a spectrophotometer. An AvaSpec-2018L grating spectrophotometer was exploited to integrate the spectrally dispersed PL response. Over $10^{3} \mathrm{PL}$ transients were integrated and averaged to get the scintillation spectrum in the samples irradiated with the fixed reactor neutron fluence. The PL spectra recorded on pristine and irradiated AT GaN samples provided evolution of scintillation efficiency within various spectral bands.

\subsection{Positron annihilation spectroscopy}

For PAS experiments, the pristine and $1 \times 10^{16} \mathrm{~cm}^{-2}$ as well as $5 \times 10^{16} \mathrm{~cm}^{-2}$ neutron fluence irradiated samples were employed. As the pristine samples contain significant concentrations of vacancy complexes, usage of rather low fluences is insufficient to produce detectable densities of radiation defects 24. 25. Positrons implanted into the sample are captured and localized at neutral and negative vacancies. It is possible to determine the concentration of vacancies as well as to distinguish between different types of vacancies $\left(\mathrm{V}_{\mathrm{Ga}}, \mathrm{V}_{\mathrm{Ga}}-\mathrm{O}_{\mathrm{N}}, \mathrm{V}_{\mathrm{Ga}}-\mathrm{H}_{\mathrm{n}}\right)$ 24, 25]. The Mgdoped $\left(1 \times 10^{20} \mathrm{~cm}^{-3}\right)$ pristine non-annealed AT $\mathrm{GaN}$ sample was used as a reference - possible extraction of the annihilation parameters of the $\mathrm{GaN}$ lattice has been shown [24]. The pristine and neutron-irradiated AT GaN samples were examined at room temperature (RT), using a digital positron lifetime spectrometer with a Gaussian time resolution of 250 ps. Two identical pristine samples were sandwiched together with the ${ }^{22} \mathrm{Na} \mu \mathrm{Ci}$ positron source foiled in $1.5 \mu \mathrm{m}$ thick aluminium. To have the PAS spectrum, the positron lifetime records of $10^{6}$ positron annihilation (PA) events were collected. The PAS measurements for irradiated samples were made using the same source, but with a different sandwich-structure (the source between the pristine and the irradiated samples). In the latter case, 
the $2 \times 10^{6}$ events were accumulated to record a PA spectrum and the spectrum of the pristine sample was subtracted in the analysis. The spectrum of the positron decay $P(t)$ (after subtracting the constant background) due to annihilations in the source material ( $\mathrm{Al}$ foil $210-215 \mathrm{~ns}, \mathrm{NaCl}$ $400 \mathrm{~ns}$ and positronium $1500 \mathrm{~ns}$ [23]) was analysed assuming the sum of the exponential components

$$
P(t)=\sum_{i} I_{i} \mathrm{e}^{-t / \tau_{i}},
$$

where positrons in the state $i$ annihilate with the lifetime $\tau_{i}$ and the intensity $I_{i}$. The increase of the average lifetime $\tau_{\text {ave }}$ [23] above the bulk lattice lifetime $\tau_{\mathrm{b}}$ indicates that positrons annihilate as trapped at vacancy defects. Moreover, this parameter is insensitive to the fitting procedures, and even a change of 1 ps in its value can be resolved [23]. The $\tau_{b}$ parameter is the positron lifetime in the delocalized state in the lattice, and $\tau_{\mathrm{v}}\left(\tau_{2}\right.$ in a twocomponent spectrum) is the lifetime component that gives directly the vacancy-specific lifetime. Because the electron density at a vacancy is lower than that within the bulk, the lifetime $\tau_{\mathrm{v}}$ is always longer than the bulk lifetime $\tau_{\mathrm{b}}$. The first lifetime component is $\tau_{1}=\left(\tau_{\mathrm{b}}{ }^{-1}+\kappa_{\mathrm{v}}\right)^{-1}<\tau_{\mathrm{b}}$, where $\kappa_{\mathrm{v}}$ is the positron trapping rate at one species of vacancy defects:

$$
\kappa_{\mathrm{v}}=c_{\mathrm{v}} \mu_{\mathrm{v}}
$$

Here $c_{\mathrm{v}}$ denotes the vacancy concentration and $\mu_{\mathrm{v}}$ is the positron trapping coefficient, which strongly depends on the charge-state of the vacancy defect. The bulk lifetime $\tau_{\mathrm{b}}$ of $\mathrm{GaN}$ is approximately $\tau_{\mathrm{b}}=160 \mathrm{ps}$, as measured in the reference sample. The parameter $\tau_{\mathrm{v}}$ depends on defect species, it varies in the range 220-240 ps for $\mathrm{V}_{\mathrm{Ga}}$ and $\mathrm{V}_{\mathrm{Ga}}$ complexes with a single $\mathrm{O}$ or $\mathrm{H}$ atom. This is clearly less than $200 \mathrm{ps}$ for $\mathrm{V}_{\mathrm{Ga}}$-multi-hydrogen complexes [25]. It is likely that $\mathrm{V}_{\mathrm{Ga}}$ complexed with 3 or more hydrogen atoms do not trap positrons [23, 25]. Typical positron trapping coefficients are $\mu_{\mathrm{v}}=1 \times 10^{15} \mathrm{~s}^{-1}$ for neutral vacancies and $\mu_{\mathrm{v}}=2-3 \times 10^{15} \mathrm{~s}^{-1}$ for negatively charged vacancies at RT, respectively.

\section{Evolution of the PPI spectra}

The PPI spectra have been recorded at room temperature on AT GaN:Mg and AT GaN:Mn. The photoionization spectrum is obtained as the MW-PC peak-signal amplitude, proportional to the excess carrier density generated by photoionization, which depends on photon energy. The evolution of the PPI spectra with neutron fluence are illustrated in Fig. 1 for AT GaN:Mn (a) and AT GaN:Mg (b), respectively.

The step-like photoionization spectra contained four spectral peaks for AT GaN:Mn (Fig. 1(a)) and seven peaks for AT GaN:Mg samples (Fig. v(b)), obtained by fitting the recorded PPI spectra.

The PPI spectral steps $\mathrm{E}_{\mathrm{Mn}, 1}$ and $\mathrm{E}_{\mathrm{Mn}, 2}$ are nearly independent of neutron irradiation (Fig. 11(a)). With fluence enhancement, a few times reduction (relative to that obtained for the pristine sample) of the PPI spectral step of $\mathrm{E}_{\mathrm{Mn}, 4}$ can be deduced
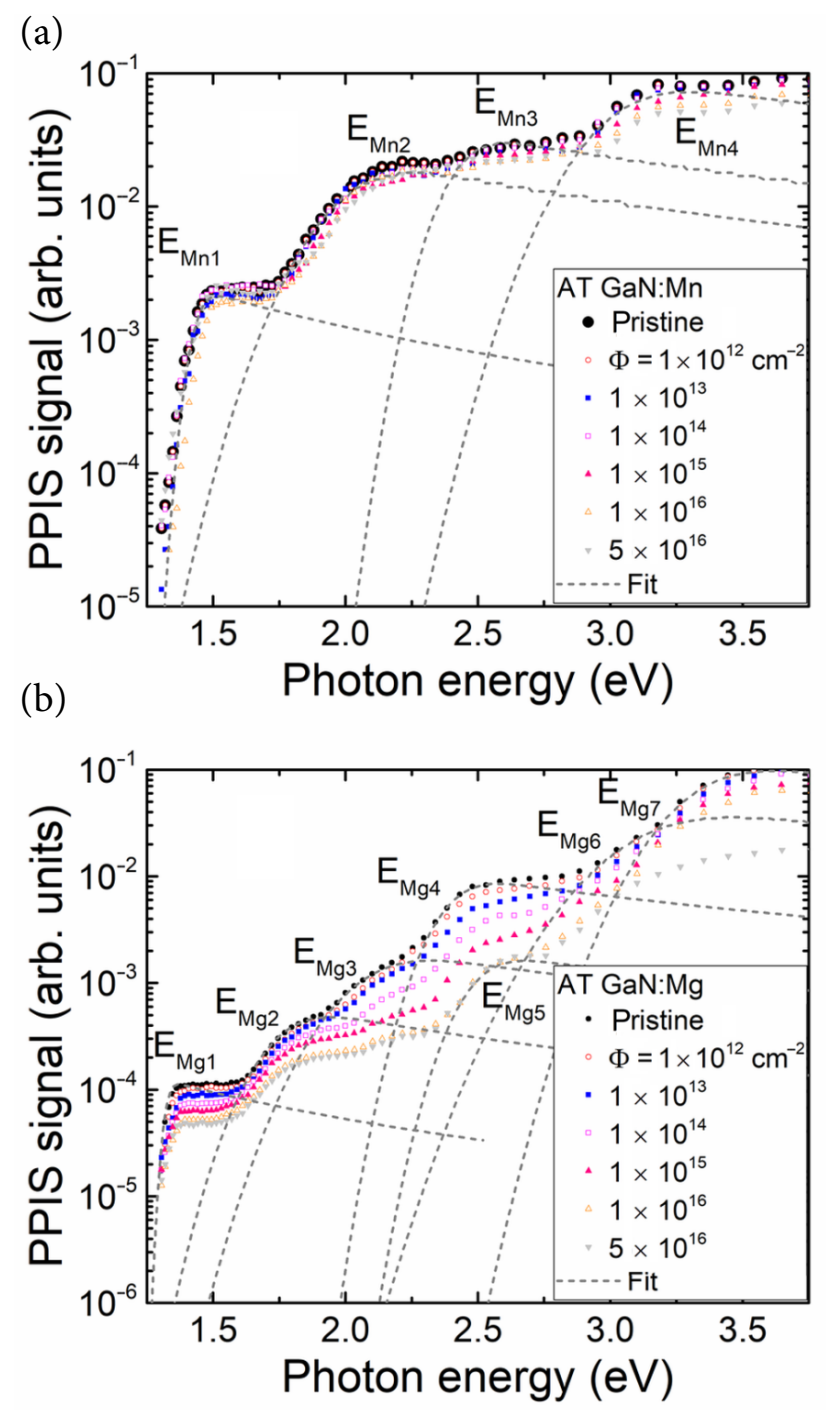

Fig. 1. (Coloured online.) Fitting of the PPI spectra, recorded on the pristine and neutron-irradiated samples (AT GaN:Mn (a) and AT GaN:Mg (b)). Thin dash lines show the PPIS steps simulated using Eqs. (1) and (2). 
from Fig. 1(a). This implies the decrease of concentration (proportional to the height of the PPIS step) of this $\mathrm{E}_{\mathrm{Mn}, 4}$ definite trap of the same origin (with an invariable cross-section). The insignificant variation of the $\mathrm{E}_{\mathrm{Mn}, 3}$ trap density can also be implied from the fluence-dependent evolution of Mn-doped AT GaN (in Fig. 1(a)). The decrease of concentration of the initially existing defects formed by crystal growth can be explained by defect transformations. Really, such a transformation of Mn ascribed defects has been revealed by ESR spectroscopy in our previous study [33]. On the other hand, the carrier lifetime reduction (observed on these samples [33]) with enhancement of neutron fluence seems to be the main reason for the reduced initial filling of $\mathrm{E}_{\mathrm{Mn}, 4}$ traps.

In Table 1, the identified activation energies and values of the broadening factor are listed for the predominant centres in Mn-doped AT GaN samples. The threshold photoionization energy values, taken from literature, were compared with those, extracted from fitting of the PPIS peaks, and these values have been employed for identifying of the defects. The density of the Mn associated traps $\mathrm{E}_{\mathrm{Mn}, 1}$ and $\mathrm{E}_{\mathrm{Mn}, 2}$ seems to be independent of neutron irradiation fluence, despite this the impact of the carrier lifetime decrease is the same for all the resolved traps $\mathrm{E}_{\mathrm{Mn}, 1}-\mathrm{E}_{\mathrm{Mn}, 4}$. This hints that the PPIS step height highlights the initial filling state of the definite photoactive trap. Thereby, radiation defects seem to make the biggest impact on the initial filling of the $\mathrm{E}_{\mathrm{Mn}, 4}$ centres, however, of unknown origin.

A rather different evolution (relative to $\mathrm{Mn}$ doped AT GaN material) of the PPIS steps was obtained in Mg-doped AT GaN samples (Fig. 1(b)). The most resolvable changes of the height of PPI
$\mathrm{E}_{\mathrm{Mg}, 3}-\mathrm{E}_{\mathrm{Mg}, 5}$ spectral steps were obtained. The ESR spectroscopy, performed on these $\mathrm{Mg}$-doped AT GaN samples [33], showed prevailing of the gallium vacancy and substitutional oxygen $\left(\mathrm{V}_{\mathrm{Ga}}{ }^{-}\right.$ $\mathrm{O}_{\mathrm{N}}$ ) [33, 39, 40] defects in the pristine material and hinted on the appearance of the nitrogen split interstitial [33, 41, 42] defects under irradiation. However, longer carrier lifetimes (relative to the Mndoped material) and existence of a small density of $\mathrm{Mn}$ impurities in the pristine Mg-doped AT GaN samples were evidenced [33]. A significant decrease (up to an order of magnitude) of the height of the $\mathrm{E}_{\mathrm{Mg}, 3}-\mathrm{E}_{\mathrm{Mg}, 4}$ spectral steps has been obtained in this study, while less changes of the PPIS signals have been revealed for $\mathrm{E}_{\mathrm{Mg}, 1}$ and $\mathrm{E}_{\mathrm{Mg}, 2}$ spectral steps. Moreover, nearly invariable height has been observed for the $\mathrm{E}_{\mathrm{Mg}, 7}$ spectral step with enhancement of the neutron fluence. For the Mg-doped samples, appearance of the additional PPIS centre $\mathrm{E}_{\mathrm{Mg}, 5}$ in the range of elevated fluences $\left(>10^{14} \mathrm{n} / \mathrm{cm}^{2}\right)$ can be deduced from Fig. 1(b). The capture crosssection values for all the mentioned traps are nearly the same. This implies that neutron irradiation governs only the initial filling (density of carriers on the definite type centres) of the technologically induced defects.

Values of the estimated activation energy and the broadening factor for different traps are listed in Table 1 for the predominant centres in the Mgdoped AT GaN samples. There, the traps associated with vacancies, interstitials, impurities and dopants are tentatively identified. The amplitudes of different components, which are proportional to the initial filling of the photoactive centres, are plotted in Fig. 2. It can be inferred that neutron irradiations do not change considerably the structure of the photoactive technological defects. In

Table 1. The PPIS parameters in the pristine and neutron-irradiated samples extracted by fitting the PPIS steps.

\begin{tabular}{|c|c|c|c|c|c|c|c|c|c|c|c|}
\hline & \multicolumn{4}{|c|}{ AT GaN:Mn } & \multicolumn{7}{|c|}{ AT GaN:Mg } \\
\hline & $\mathrm{E}_{\mathrm{Mn} 1}$ & $\mathrm{E}_{\mathrm{Mn} 2}$ & $\mathrm{E}_{\mathrm{Mn} 3}$ & $\mathrm{E}_{\mathrm{Mn} 4}$ & $\mathrm{E}_{\mathrm{Mg} 1}$ & $\mathrm{E}_{\mathrm{Mg} 2}$ & $E_{\mathrm{Mg} 3}$ & $\mathrm{E}_{\mathrm{Mg} 4}$ & $\mathrm{E}_{\mathrm{Mg} 5}$ & $\mathrm{E}_{\mathrm{Mg} 6}$ & $\mathrm{E}_{\mathrm{Mg} \mathrm{\gamma}}$ \\
\hline$E_{d} \pm 0.04(\mathrm{eV})$ & 1.43 & 1.99 & 2.41 & 2.99 & 1.32 & 1.74 & 2.06 & 2.38 & 2.48 & 3.10 & 3.31 \\
\hline$\Gamma_{d}$ & 0.06 & 0.25 & 0.15 & 0.26 & 0.03 & 0.18 & 0.24 & 0.15 & 0.15 & 0.32 & 0.25 \\
\hline Defect type & $\frac{\bar{g}}{\stackrel{\tilde{J}}{\xi}}$ & $\begin{array}{l}\frac{F}{E} \\
\stackrel{F}{\Sigma}\end{array}$ & 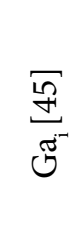 & $\overleftrightarrow{\measuredangle}$ & 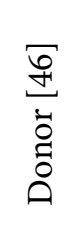 & 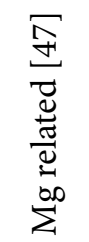 & 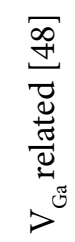 & 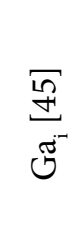 & 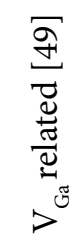 & 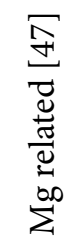 & $\frac{\sqrt[D]{ \pm}}{p^{z}}$ \\
\hline
\end{tabular}




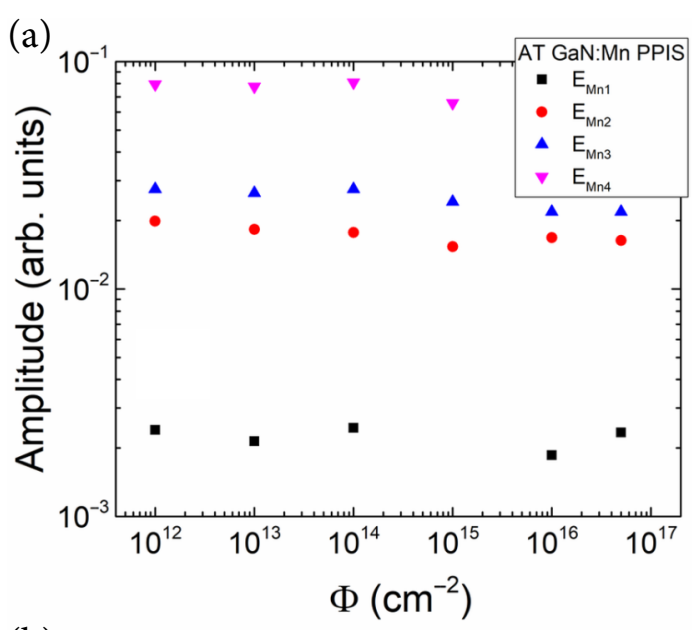

(b)

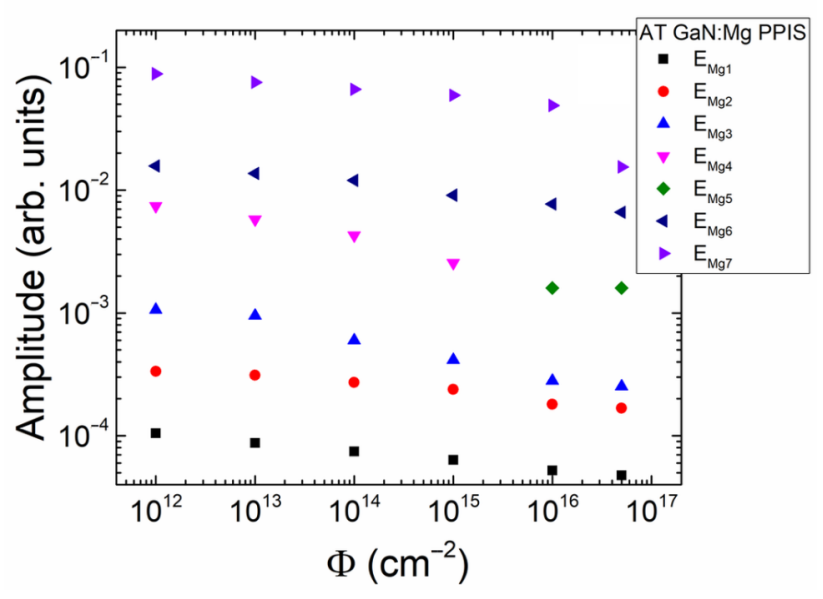

Fig. 2. (Coloured online.) Amplitudes of the PPI spectrum components, proportional to the initial filling of different traps, estimated from fitted PPI spectra for the pristine and neutron-irradiated samples (AT GaN:Mn (a) and AT GaN:Mg (b)), as functions of neutron irradiation fluence.

the Mg-doped sample, the radiation-induced defect $\mathrm{E}_{\mathrm{Mg} 5}$ is only observable for the samples irradiated with elevated fluences of $>10^{14} \mathrm{n} / \mathrm{cm}^{2}$. The latter defect can play the role of a fast recombination centre. Its impact appears only when the carrier lifetime, linked to this radiation defect, becomes shorter than that inherent for the pristine material.

\section{Evolution of the photoluminescence spectra}

The neutron fluence $\Phi$ dependent evolution of the UV pulse excited photoluminescence (PL) spectra ex situ recorded in Mn (a) and Mg (b) doped AT GaN is illustrated in Fig. 3.

In Mn-doped AT GaN (Fig. 3(a)), a rather wide spectral band peaked at $2.5 \mathrm{eV}$ appears in the yellowgreen (YG) PL range. The low intensity blue (B) PL peaked at $3 \mathrm{eV}$ can also be deduced from these (Fig. 3(a)) spectra. A clear decrease of the intensity of the YG-PL band with the enhancement of fluence is clearly observed only for large fluences $>10^{16} \mathrm{n} / \mathrm{cm}^{2}$. The intensity of B-PL decreases nearly monotonically with the increase of irradiation fluence.

In the PL spectra recorded for Mg-doped AT samples (Fig. 3(c)), the same PL bands appear. However, the intensity of the B-PL wing is larger in this material relative to that in Mn-doped AT GaN. Moreover, the intensity of both YG-PL and B-PL is nearly invariable up to irradiations with moderate fluences $<10^{15} \mathrm{n} / \mathrm{cm}^{2}$. A clear reduction of the PL intensity appears only for $\Phi \geq 10^{15} \mathrm{n} / \mathrm{cm}^{2}$. This intensity reduction is most expressed for the B-PL spectral wing.

It is very probable that wide PL bands (especially YG-PL) are composed of several overlapping PL peaks. These peaks can be predicted by correlating PPI and PL spectra in consideration of the conversion from absorption to emission.

The absorption centres resolved within PPIS (Fig. 1) may originate the Stokes shifted PL bands. These YG-PL and B-PL peaks were fitted (Fig. 3) by using the van Roosbroeck-Shockley (vR-S) approach [50, 51] in relating the conversion from the PPI to PL spectra. The rate $\Delta R(h v)$ of the emission via the trap of photo-activation energy $E_{d}$ is linked to the photon-electron interaction crosssection $\sigma(h v)$, whose value also covers the B- and YG-PL peak photon energy (assigned to PL as $\left.\sigma_{d P L}(h v)\right)$ and is expressed as follows:

$$
\begin{aligned}
& \Delta R_{d}(h v)=\frac{n_{\mathrm{ex}, \Delta(h v)}}{\tau_{\mathrm{PL}, \Delta(h v)}}= \\
& \rho_{d, \mathrm{PL}}\left(\frac{h v}{k_{\mathrm{B}} T}\right) \sigma_{d, \mathrm{PL}}\left(h v / k_{\mathrm{B}} T\right) N_{d} \frac{n_{\mathrm{ex}, \Delta(h v)} N_{d}}{n_{\mathrm{i}}^{2}} .
\end{aligned}
$$

Here $n_{\mathrm{i}}=2 \times 10^{-10} \mathrm{~cm}^{-3}$ is the intrinsic carrier concentration for $\mathrm{GaN}$ materials [52], $k_{\mathrm{B}}$ is the Boltzmann constant, $h$ is the Planck constant, $\rho_{a}$ is the surface density of photons ascribed to the unit frequency $v$ within the absorption spectrum for the spectral range $\Delta(h v)$, inherent to the dedicated trap of the concentration $N_{d}$, and $n_{\text {ex } \Delta(h v)}$ is the excess carrier density generated through photoionization in the definite spectral range $\Delta(h v), \tau_{\mathrm{PL} \Delta(h v)}$ is the PL relaxation time.

The relations between the photoionization and photoluminescence spectra (Fig. 3) were simulated 


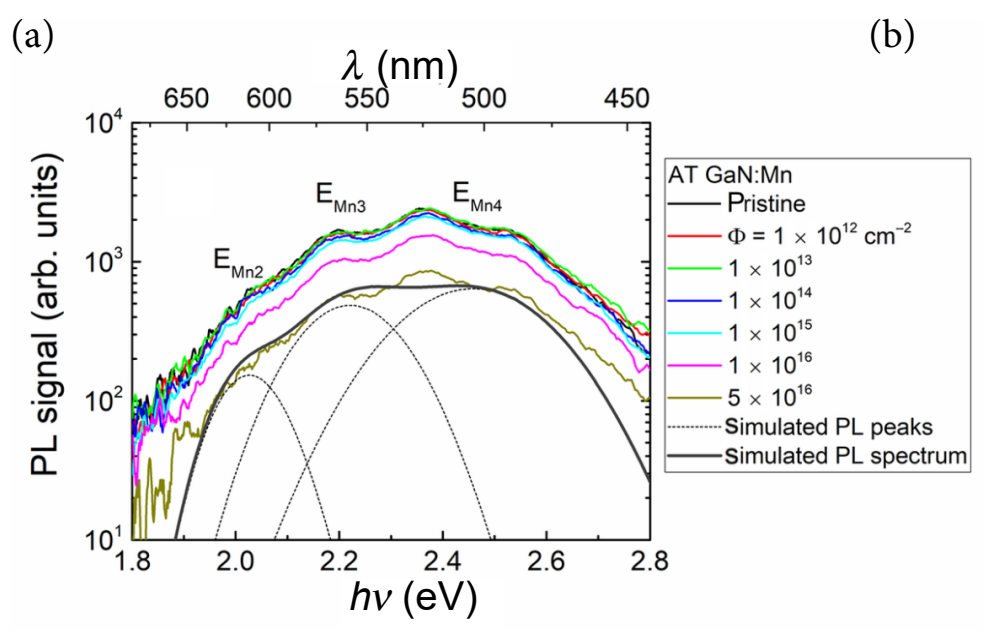

(c)

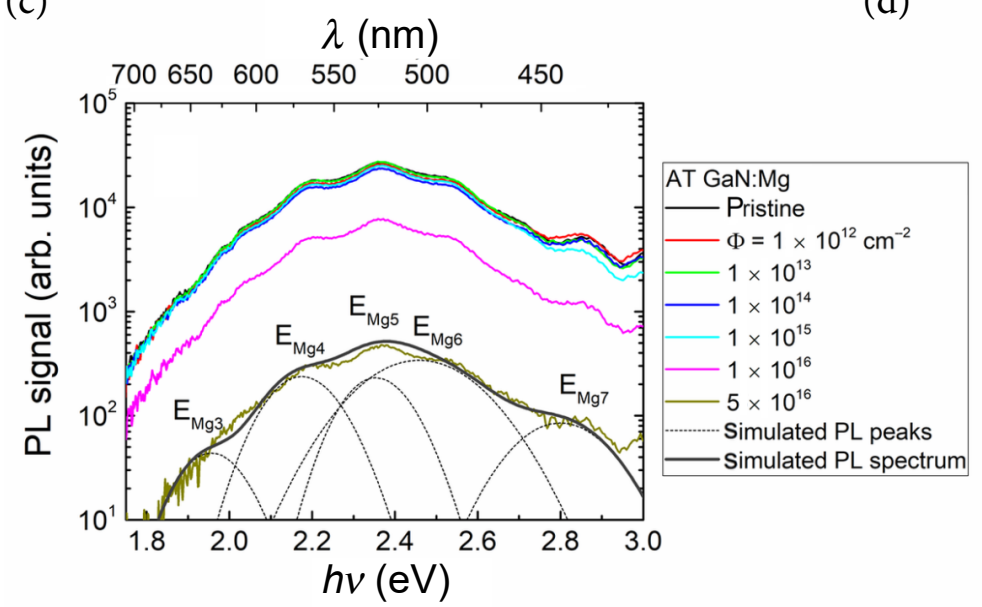

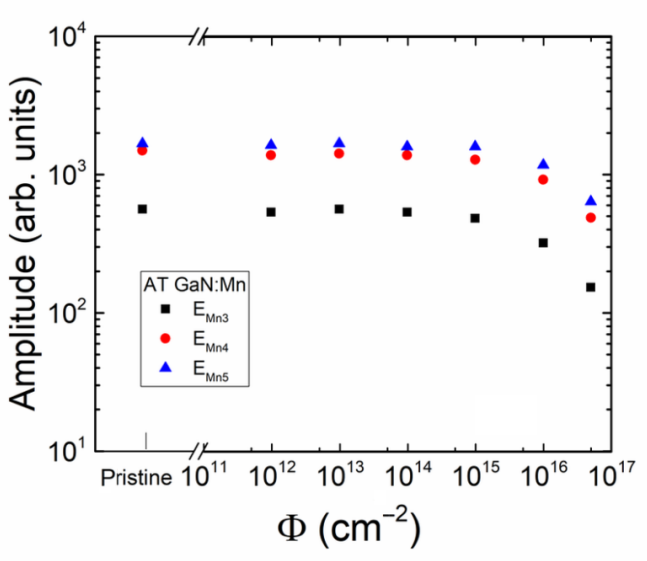

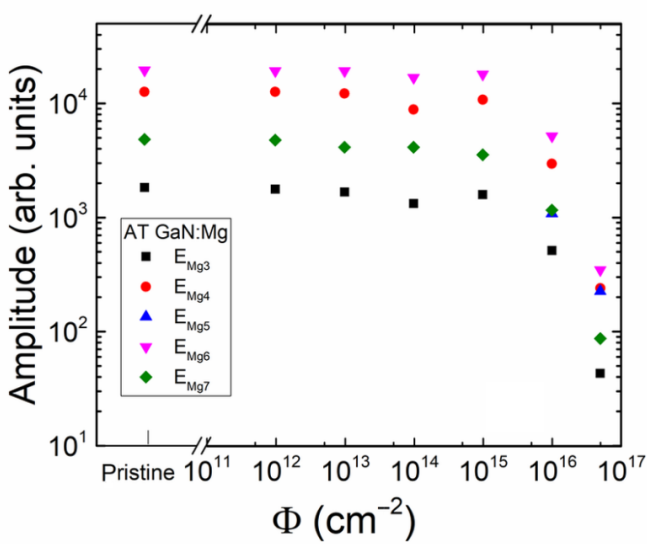

Fig. 3. (Coloured online.) Recorded and fitted evolution of photoluminescence spectra (a, c), using PPIS experimental data (listed in Table 1), and the amplitudes of the fitted PL spectral components (b, d), extracted for AT GaN:Mn (a, b) and AT GaN:Mg (c, d) materials, respectively. Thin dash lines represent PL peaks simulated using Eqs. (1) and (6), a thick grey line shows a resultant PL spectrum composed of the simulated PL peaks.

using Eqs. (1, 2, 3). The comparison of the simulated photoionization and photoluminescence spectra ascribed to several PPIS steps is illustrated in Fig. 3. For neutron-irradiated materials, the structure of Band YG-PL was reproduced by varying the $N_{d}^{*}$ value with irradiation fluence which means variation of the filling level of definite centres. Simulations were performed using the extracted values of the crosssection of the photon-electron coupling $\sigma_{d}(h v)$ and of the photoionization energy $E_{d}$ (as well as broadening factors $\Gamma_{d}$ ) and by adjusting the $\sigma_{d \mathrm{PL}}(h v)$ function to fit $I_{\mathrm{PL}}(h v)$ spectral peaks comprising a rather broad PL band. An association of the PPIS steps to the definite PL peaks is also sketched in Fig. 3 by denoting the respective deep traps $\left(E_{i}, i=2-7\right.$ according to notifications in Table 1).

A rather good reconstruction of the PL components, necessary for composing of wide PL spectral bands, was obtained by simulating (using vR-S approach) the experimental PL (Fig. 3(a, c)). The evolution of the amplitudes of different PL spectral components with neutron irradiation fluence is illustrated in Fig. 3(b, d) for GaN:Mn and GaN:Mg materials, respectively. The simulations of PIS and PL spectra show that the additional radiation-induced trap $\mathrm{E}_{\mathrm{Mg}, 5}$ PPIS peak is very probable. Based on these fits it can be inferred that existence of technological defects in AT GaN:Mn is the main reason for the appearance of YG-PL. The richer PPI and PL spectra, recorded on AT GaN:Mg, and their modifications with neutron irradiation are determined by a variety of technological defects, the filling level of which changes with the appearance of fast non-radiative recombination centres, and radiation-induced additional photoactive traps. There, the faster reduction of the amplitudes of different PL spectral components 
(Fig. B (b, d)) in comparison with the PPIS component amplitudes (Fig. 2( $(a, b)$ ) can be explained by the additional (relative to the initial filling of definite traps) decrease of excess carrier concentration (the term $n_{\text {ex } \Delta(h v)}$ in Eq. 2) through non-radiative decay channels. The B and YG bands are assigned to $\mathrm{Mg}$ impurities and Ga-vacancy complexes in $\mathrm{Mg}$ doped AT GaN material [53]. Vacancy complexes are plausible centres responsible for luminescence variations with neutron fluence when generation of radiation vacancies is very probable. Vacancy complexes with oxygen $\left(\mathrm{V}_{\mathrm{Ga}}-\mathrm{O}_{\mathrm{N}}\right)$ or silicon $\left(\mathrm{V}_{\mathrm{Ga}}-\mathrm{Si}_{\mathrm{Ga}}\right)$ might be responsible for $\mathrm{YG}$ luminescence. Additionally, $\mathrm{C}_{\mathrm{N}}-\mathrm{O}_{\mathrm{N}}$ technological defects may also be a reason for $\mathrm{YG}$ luminescence [54]. It seems that $\mathrm{Ga}$ vacancies are most probable non-radiative recombination centres. By generalizing the PL data, a significant reduction of the overall PL intensity is quite evident (Fig. 3(b, d)). Also the overall PL intensity appears lower in the Mn-doped material from the very beginning. The dominant traps can tentatively be estimated by using the algebra of the obtained photo-activation energy values relative to a band gap $\left(E_{\mathrm{G}}=3.45 \mathrm{eV}\right.$ [50]) as well as valence/conduction band edges and to the identified PPIS traps as well as B and YG range PL transitions. Thereby, $E_{1-\mathrm{PPIS}}=1.4 \mathrm{eV}$ can be resulted from $E_{\mathrm{G}}-$ $h v_{2} \approx 1.3 \pm 0.1 \mathrm{eV}$.

\section{Irradiation-induced vacancy defects observed by positron annihilation spectroscopy}

Figure 4 shows the average positron lifetime measured at RT in the pristine and neutron-irradiated AT GaN:Mn and AT GaN:Mg samples. The positron lifetime spectra consisted of only one resolvable component, suggesting saturation trapping at $\mathrm{V}_{\mathrm{Ga}}$ hydrogen complexes and also a contribution from negative ions ( $\mathrm{Mn}$ and $\mathrm{Mg}$ ), as discussed for the case of AT GaN in detail in Refs. [23-25]. Nevertheless, important conclusions can be drawn from the average positron lifetime. First, the average positron lifetime in the pristine AT GaN:Mn and AT GaN:Mg is clearly longer than the bulk lifetime of 160 ps, indicating that positrons are trapped at vacancy defects in these samples. Moreover, the average positron lifetime is longer in pristine AT GaN:Mn than that in AT GaN:Mg, indicating that the total amount of the open volume is larger in AT GaN:Mn, suggesting that the concentration of the Ga vacancy related

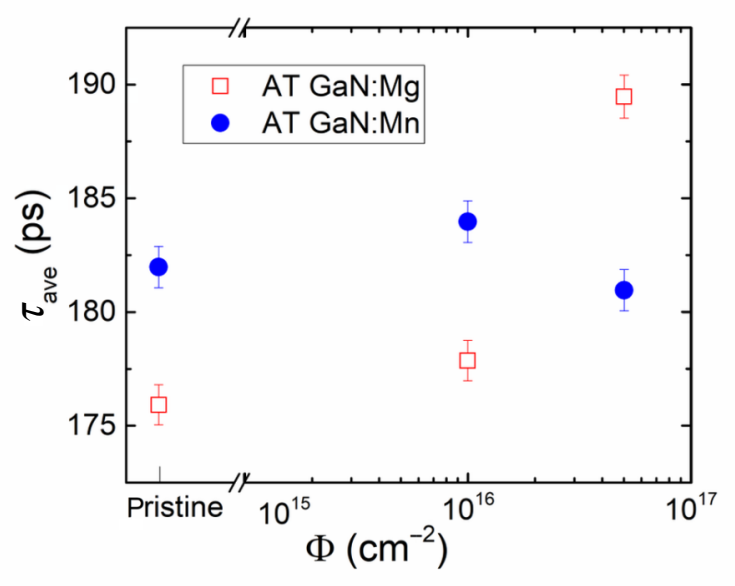

Fig. 4. (Coloured online.) Average positron lifetime in pristine and neutron-irradiated AT GaN:Mn and AT GaN:Mg.

defects is higher. Other possible explanations, namely that the vacancy defects would be larger (that is, contain less hydrogen) in AT GaN:Mn or that AT $\mathrm{GaN}: \mathrm{Mg}$ would contain more negative ions (that in $\mathrm{GaN}$ affect the data also at RT to some extent), are considered unlikely. Also, the hydrogen content in the samples is similar, and the Mn doping is higher (by a factor of two) than the Mg doping.

The average positron lifetime increases significantly after neutron irradiation in AT GaN:Mg, in particular at a higher fluence of $5 \times 10^{16} \mathrm{~cm}^{-2}$. This indicates the introduction of Ga vacancy defects in the irradiation process, similarly as observed after, e.g. electron irradiation and hydrogen implantation [37, 38]. As the vacancy defect concentrations in the pristine AT GaN samples are likely to be of the order of $10^{18} \mathrm{~cm}^{-3}$ (or more due to the saturation phenomenon discussed in Ref. [25]), at least similar concentrations of vacancy defects are introduced in the neutron-irradiated samples with the higher fluence. Interestingly, the average positron lifetime is hardly affected by the neutron irradiation in the AT GaN:Mn samples, although the concentrations of the irradiation-induced vacancy defects are necessarily the same as in AT GaN:Mg. This supports the interpretation that the vacancy defect concentrations are significantly higher in AT GaN:Mn than those in the AT GaN:Mg samples in the pristine material.

\section{Discussion}

The positron annihilation spectroscopy (PAS) data show that the pristine AT GaN:Mn material 
contains a higher concentration of vacancy defects than AT GaN:Mg. This is seen both as a higher average lifetime of positrons in the pristine material, and also by the neutron irradiation having very little effect on the average lifetime in AT GaN:Mn. In contrast, in AT GaN:Mg, the irradiation (in particular with the highest fluence) causes a strong increase in the vacancy defect concentrations observed by the increase of the positron average lifetime. This is equivalent to an increase in the average size of the open volume in the vacancies. The increase of the positron average lifetime is related (as we have shown earlier [24, 25]) to the fact that the ingrown $\mathrm{Ga}$ vacancies in $\mathrm{AT}$ $\mathrm{GaN}$ are present in hydrogen complexes that produce a shorter lifetime than 'pure' $\mathrm{V}_{\mathrm{Ga}}$ produced by the irradiation. It means that the concentration of irradiation-induced vacancies is significant compared to the concentration of the ingrown vacancies (Mg-doped) if the average open volume at the vacancies observed with positrons increases. Also, it means that the concentrations of the ingrown vacancies in Mn-doped AT GaN are significantly higher than those created by irradiation, even at the highest fluence, when no changes of the positron lifetime are observed.

The comparison of the PAS and PL data shows that the $\mathrm{Ga}$ vacancies produced by irradiation are non-radiative recombination centres. The significant reduction of the overall PL intensity with the enhancement of neutron fluence nicely correlates with the positron annihilation data. This effect is stronger in the Mg-doped material; as the ingrown Ga vacancy-hydrogen complexes are probably also detrimental for the PL intensity in general, the Mndoped material appears to luminesce less than the pristine Mg-doped material. Also, the stronger irradiation effect in the Mg-doped materials supports this hypothesis. Moreover, this comparison between the $\mathrm{Mg}$ - and $\mathrm{Mn}$-doped materials evidences the smaller effect in the Mn-doped samples, where the pristine vacancy concentrations seem to be higher, as the irradiation-induced vacancies affect the positron lifetime data so little.

\section{Conclusions}

The decrease of concentration of the initially existing defects formed by crystal growth has been observed after neutron irradiation and it can be explained by defect transformations. This defect transformation effect of $\mathrm{Mn}$-ascribed defects was revealed by ESR spectroscopy. The carrier lifetime reduction (observed for these samples) with the enhancement of neutron fluence seems to be the main reason for the reduced initial filling of $\mathrm{E}_{\mathrm{Mn}, 4}$ traps. The density of the Mn associated traps $\mathrm{E}_{\mathrm{Mn}, 1}$ and $\mathrm{E}_{\mathrm{Mn}, 2}$ seems to be independent of neutron irradiation fluence; despite this the impact of the carrier lifetime decrease is the same for all the resolved traps $\mathrm{E}_{\mathrm{Mn}, 1}-\mathrm{E}_{\mathrm{Mn}, 4}$. This hints that the PPIS step height highlights the initial filling state of the definite photoactive trap. Thereby, radiation defects seem to make the biggest impact on the initial filling of the $\mathrm{E}_{\mathrm{Mn}, 4}$ centres of unknown origin. The most resolvable changes of the height of PPI $\mathrm{E}_{\mathrm{Mn}, 3}-\mathrm{E}_{\mathrm{Mn}, 4}$ spectral steps have been obtained.

A rather different evolution (relative to the Mndoped AT GaN material) of the PPIS steps has been obtained in the Mg-doped AT GaN samples. The longer carrier lifetimes (relative to the Mndoped material) and existence of a small density of Mn impurities in the pristine Mg-doped AT GaN samples have been evidenced by EPR. The significant decrease (up to an order of magnitude) of the height of the $\mathrm{E}_{\mathrm{Mg}, 3}-\mathrm{E}_{\mathrm{Mg}, 4}$ spectral steps has been obtained with the enhancement of neutron irradiation fluence. Meanwhile, less changes of the PPIS signals have been revealed for $\mathrm{E}_{\mathrm{Mg}, 1}$ and $\mathrm{E}_{\mathrm{Mg}, 2}$ spectral steps and nearly invariable height has been observed for the $\mathrm{E}_{\mathrm{Mg}, 7}$ spectral step with the enhancement of neutron fluence. For the Mg-doped samples, the appearance of the additional PPIS centre $\mathrm{E}_{\mathrm{Mg}, 5}$ in the range of elevated fluences $\left(>10^{14} \mathrm{n} /\right.$ $\mathrm{cm}^{2}$ ) has been deduced. It has been concluded that neutron irradiation governs only the initial filling (density of carriers on the definite type centres) of the technologically ingrown defects.

The traps associated with vacancies, interstitials, impurities and dopants have been tentatively identified. It has been inferred that neutron irradiations do not change considerably the structure of the photoactive technological defects. The radiation induced defect $\mathrm{E}_{\mathrm{Mg}, 5}$ is only observable for the samples irradiated with the elevated fluence of $>10^{14} \mathrm{n} / \mathrm{cm}^{2}$. The latter defect can play the role of a fast recombination centre whose impact appears only when the carrier lifetime, linked to this radiation defect, becomes shorter than that inherent for the pristine material. 
The relations between the photoionization and photoluminescence spectra have been simulated using the van Roosbroeck-Shockley approach. For neutron-irradiated materials, the structure of Band YG-PL has been reproduced by varying the $N_{d}^{*}$ value with irradiation fluence which means variation of the filling level of definite centres. An association of the PPIS steps to the definite components of the PL bands has been performed. A rather good reconstruction of the PL components, necessary for composing of the wide PL spectral bands, has been obtained by simulating the experimental PL spectra. The evolution of the amplitudes of different PL spectral components with neutron irradiation fluence has been obtained. The richer PPI and PL spectra, recorded on AT GaN:Mg, and their modifications with neutron irradiation are determined by the wider variety of technological defects, the filling level of which changes with the appearance of fast non-radiative recombination centres, and radiation-induced additional photoactive traps. The faster reduction of the amplitudes of different PL spectral components in comparison with the PPIS component amplitudes can be explained by the additional decrease of the excess carrier concentration $n_{\text {ex } \Delta(h v)}$ through the non-radiative decay channels. Vacancy complexes with oxygen $\left(\mathrm{V}_{\mathrm{Ga}}-\mathrm{O}_{\mathrm{N}}\right)$ or silicon $\left(\mathrm{V}_{\mathrm{Ga}}-\mathrm{Si}_{\mathrm{Ga}}\right)$ might be responsible for $\mathrm{YG}$ luminescence. $\mathrm{Ga}$ vacancies are most likely non-radiative recombination centres. This is supported by the PL data. Additionally, $\mathrm{C}_{\mathrm{N}}-\mathrm{O}_{\mathrm{N}}$ technological defects may also be a reason for YG luminescence. The positron annihilation data support the hypothesis that Ga vacancies are non-radiative recombination centres and show that the Mn-doped material has more vacancies than the Mg-doped material.

\section{Acknowledgements}

This research is funded by the European Social Fund under Measure No. 09.3.3- LMT-K-712 -020012 'Development of Competences of Scientists, other Researchers and Students through Practical Research Activities'. The authors are indebted to Dr. M. Zając for providing the AT GaN materials. The neutron irradiations at the TRIGA Facility were supported by the AIDA-2020 Transnational Access Project funded by the EU Horizon 2020 R\&D Programme under Grant Agreement No. 654168.

\section{References}

[1] P. Pittet, P. Jalade, G. Gindraux, P. Guiral, R. Wanga, J.M. Galvan, and G.N. Lua, DoRGaN: Development of quality assurance and quality control systems for high dose rate brachytherapy based on GaN dosimetry probes, IRBM 39, 279-290 (2018), https://doi.org/10.1016/j. irbm.2018.04.005

[2] S.J. Pearton, B.S. Kang, S. Kim, F. Ren, B.P. Gila, C.R. Abernathy, J. Lin, and S.N.G. Chu, GaNbased diodes and transistors for chemical, gas, biological and pressure sensing, J. Phys. Condens. Matter 16, R961-R994 (2004), https://doi. org/10.1088/0953-8984/16/29/R02

[3] https://home.cern/science/accelerators/high-luminosity-lhd

[4] https://home.cern/science/accelerators/futurecircular-collider

[5] O. Kortner, S. Kortner, H. Kroha, S. Podkladkin, and R. Richter, Design of the FCC-hh muon detector and trigger system, Nucl. Instrum. Methods Phys. Res. A 936, 447-448 (2019), https://doi. org/10.1016/j.nima.2018.10.013

[6] P.J. Sellin and J. Vaitkus, New materials for radiation hard semiconductor detectors, Nucl. Instrum. Methods Phys. Res. A 557, 479-489 (2006), https://doi.org/10.1016/j.nima.2005.10.128

[7] T. Yanagida and Y. Fujimo, Evaluation of scintillation properties of GaN, e-J. Surf. Sci. Nanotech. 12, 396-399 (2014), https://doi.org/10.1380 ejssnt.2014.396

[8] P. Pittet, G.N. Lu, J.M. Galvan, J.Y. Loisy, A. Ismail, J.Y. Giraud, and J. Balosso, Implantable real-time dosimetric probe using $\mathrm{GaN}$ as scintillation material, Sens. Actuators A Phys. 151, 29-34 (2009), https://doi.org/10.1016/j.sna.2009.02.018

[9] P. Pittet, N.L. Guo, M.G. Jean, M.B. Jean, I. Anas, Y.G. Jean, and J. Balosso, PL characterization of GaN scintillator for radioluminescence-based dosimetry, Opt. Mater. 31, 1421-1424 (2019), https://doi.org/10.1016/j.optmat.2008.09.012

[10]E. Gaubas, T. Ceponis, A. Jasiunas, V. Kovalevskij, D. Meskauskaite, J. Pavlov, V. Remeikis, A. Tekorius, and J. Vaitkus, Correlative analysis of the in situ changes of carrier decay and proton induced photoluminescence characteristics 
in chemical vapor deposition grown $\mathrm{GaN}$, Appl. Phys. Lett. 104, 62104 (2014), https://doi. org/10.1063/1.4865499

[11]H. Spieler, Semiconductor Detector Systems (Oxford University Press, New York, 2005).

[12]M. Huhtinen, Simulation of non-ionising energy loss and defect formation in silicon, Nucl. Instrum. Methods Phys. Res. A 491, 194-215 (2002), https://doi.org/10.1016/S0168-9002(02)01227-5

[13]E. Gaubas, T. Ceponis, and J. Vaitkus, Impact of generation current on evaluation of the depletion width in heavily irradiated Si detectors, J. Appl. Phys. 110, 033719 (2011), https://doi. org/10.1063/1.3619802

[14]E. Gaubas, T. Ceponis, A. Jasiunas, A. Uleckas, J. Vaitkus, E. Cortina, and O. Militaru, Correlated evolution of barrier capacitance charging, generation and drift currents and of carrier lifetime in $\mathrm{Si}$ structures during $25 \mathrm{MeV}$ neutrons irradiation, Appl. Phys. Lett. 101, 232104-1-3 (2012), https://doi.org/10.1063/1.4769370

[15]H.M. Foronda, A.E. Romanov, E.C. Young, C.A. Robertson, G.E. Beltz, and J.S. Speck, Curvature and bow of bulk GaN substrates, J. Appl. Phys. 120, 035104 (2002), https://doi. org/10.1063/1.4959073

[16]S.W. Lee, D.C. Oh, H. Goto, J.S. Ha, H.J. Lee, T. Hanada, M.W. Cho, S.K. Hong, H.Y. Lee, S.R. Cho, et al., Analysis of the relation between leakage current and dislocations in GaN-based light-emitting devices, Phys. Status Solidi 4, 37-40 (2007), https://doi.org/10.1002/pssc.200673552

[17]Z. Yu, M.A.L. Jhonson, N.A. El-Masry, J.W. Cook $\mathrm{Jr}$, and J.F. Schetzina, Study of the epitaxial-lateralovergrowth (ELO) process for GaN on sapphire, J. Cryst. Growth 195, 333-339 (1998), https://doi. org/10.1016/S0022-0248(98)00638-1

[18]M. Bockowski, M. Iwinska, M. Amilusik, M. Fijalkowski, B. Lucznik, and T. Sochacki, Challenges and future perspectives in HVPE$\mathrm{GaN}$ growth on ammonothermal GaN seeds, Semicond. Sci. Technol. 31, 93002 (2016), https:// doi.org/10.1088/0268-1242/31/9/093002

[19]M.P. D’Evelyn, H.C. Hong, D.S. Park, H. Lu, E. Kaminsky, R.R. Melkote, P. Perlin, M. Lesczynski, S. Porowski, and R.J. Molnal, Bulk GaN crystal growth by the high-pressure ammonothermal method, J. Cryst. Growth 300, 11-16 (2007), https://doi.org/10.1016/j.jcrysgro.2006.10.232

[20]J. Simon, V. Protasenko, C. Lian, H. Xing, and D. Jena, Polarization-induced hole doping in wide-band-gap uniaxial semiconductor heterostructures, Science 327, 60-64 (2010), https://doi. org/10.1126/science.1183226

[21]P. Kozodoy, M. Hansen, S.P. DenBaars, and U.K. Mishra, Enhanced Mg doping efficiency in $\mathrm{Al}_{0.2} \mathrm{Ga}_{0.8} \mathrm{~N} / \mathrm{GaN}$ superlattices, Appl. Phys. Lett. 74, 3681-3683 (1999), https://doi. org/10.1063/1.123220

[22]S. Suihkonen, S. Pimputkar, S. Sintonen, and F. Tuomisto, Defects in single crystalline ammonothermal gallium nitride, Adv. Electron. Mater. 3, 1600496 (2017), https://doi.org/10.1002 aelm.201600496

[23]F. Tuomisto and I. Makkonen, Defect identification in semiconductors with positron annihilation: Experiment and theory, Rev. Mod. Phys. 85, 1583-1631 (2013), https://doi.org/10.1103/ RevModPhys.85.1583

[24]F. Tuomisto, J.M. Maki, and M. Zajac, Vacancy defects in bulk ammonothermal GaN crystal, J. Cryst. Growth 312, 2620-2623 (2010), https:// doi.org/10.1016/j.jcrysgro.2010.04.023

[25]F. Tuomisto, T. Kuittinen, M. Zajac, R. Doradzinski, and D. Wasik, Vacancy-hydrogen complexes in ammonothermal GaN, J. Cryst. Growth 403, 114-118 (2014), https://doi.org/10.1016/j. jerysgro.2014.06.005

[26]R. Dwilinski, R. Doradzinski, J. Garczynski, L.P. Sierzputowski, A. Puchalski, Y. Kanbara, K. Yagi, H. Minakuchi, and H. Hayashi, Bulk ammonothermal GaN, J. Cryst. Growth 311, 3015-3018 (2009), https://doi.org/10.1016/j. jcrysgro.2009.01.052

[27] https://www.unipress.waw.pl/growth/index.php/ ammono-gan-wafers-sales

[28]R. Kucharski, M. Zajac, A. Puchalski, T. Sochacki, M. Bockowski, J.L. Weyher, M. Iwinska, J. Serafinczuk, R. Kudrawiec, and Z. Siemiątkowski, Ammonothermal growth of GaN crystals on HVPE-GaN seeds prepared with the use of ammonothermal substrates, J. Cryst. Growth 
427, 1-6 (2015), https://doi.org/10.1016/j.jcrysgro.2015.06.019

[29] M. Imanishi, Y. Todoroki, K. Murakami, D. Matsuo, H. Imabayashi, H. Takazawa, M. Maruyama, M. Imade, M. Yoshimura, and Y. Mori, Dramatic reduction of dislocations on a $\mathrm{GaN}$ point seed crystal by coalescence of bunched steps during $\mathrm{Na}$ flux growth, J. Cryst. Growth 427, 87-93 (2015), https://doi.org/10.1016/j.jcrysgro.2015.07.001

[30]M. Moll, Radiation tolerant semiconductor sensors for tracking detectors, Nucl. Instrum. Methods Phys. Res. A 565, 202-211 (2006), https://doi.org/10.1016/j.nima.2006.05.001

[31]L. Snoj, G.Zerovnik, and A. Trkov, Computational analysis of irradiation facilities at the JSI TRIGA reactor, Appl. Radiat. Isot. 70, 483-488 (2012), https://doi.org/10.1016/j.apradiso.2017.09.022

[32]E. Gaubas, T. Ceponis, L. Deveikis, D. Meskauskaite, S. Miasojedovas, J. Mickevicius, J. Pavlov, K. Pukas, J. Vaitkus, M. Velicka, M. Zajac, and R. Kucharski, Study of neutron-irradiated structures of ammonothermal GaN, J. Phys. D 50, 135102 (2017), https://doi.org/10.1088/1361 $6463 / \mathrm{aa} 5 \mathrm{c} 6 \mathrm{~d}$

[33]E. Gaubas, T. Čeponis, D. Meškauskaite, J. Mickevičius, J. Pavlov, V. Rumbauskas, R. Grigonis, M. Zajac, and R. Kucharski, Pulsed photoionization spectroscopy of traps in as-grown and neutron-irradiated ammonothermally synthesized GaN, Sci. Rep. 9, 1473 (2019), https://doi. org/10.1038/s41598-018-38138-6

[34]E. Gaubas, E. Simoen, and J. Vanhellemont, Review-carrier lifetime spectroscopy for defect characterization in semiconductor materials and devices, ECS J. Solid State Sci. Technol. 5, P3108-P3137 (2016), https://doi. org/10.1149/2.0201604jss

[35]A.A. Kopylov and A.N. Pikhtin, Influence of temperature on spectra of optical absorption by deep levels in semiconductors, Sov. Phys. Solid State 16, 1200-1203 (1975).

[36]A. Alkauskas, M.D. McCluskey, and C.G. Van de Walle, Tutorial: Defects in semiconductors - Combining experiment and theory, J. Appl. Phys. 119, 181101 (2016), https://doi. org/10.1063/1.4948245
[37]F. Tuomisto, V. Ranki, D.C. Look, and G.C. Farlow, Introduction and recovery of $\mathrm{Ga}$ and $\mathrm{N}$ sublattice defects in electron-irradiated GaN, Phys. Rev. B 76, 165207 (2007), https://doi.org/10.1103/ PhysRevB.76.165207

[38]F. Tuomisto, Vacancy profiles and clustering in light-ion-implanted $\mathrm{GaN}$ and $\mathrm{ZnO}$, Appl. Surf. Sci. 255, 54 (2008), https://doi.org/10.1016/j.apsusc.2008.05.172

[39]N.T. Son, C.G. Hemmingsson, T. Paskova, K.R. Evans, A. Usui, N. Morishita, T. Ohshima, J. Isoya, B. Monemar, and E. Janzén, Identification of the gallium vacancy-oxygen pair defect in GaN, Phys. Rev. B 80, 153202 (2009), https://doi. org/10.1103/PhysRevB.80.153202

[40]N.T. Son, C.G. Hemmingsson, N. Morishita, T. Ohshima, T. Paskova, K.R. Evans, A. Usui, J. Isoya, B. Monemar, and E. Janzén, Radiationinduced defects in GaN, Phys. Scr. T141, 14015 (2010), https://doi.org/10.1088/0031-8949/2010/ T141/014015

[41]H.J. Von Bardeleben, J.L. Cantin, U. Gerstmann, A. Scholle, S. Greulich-Weber, E. Rauls, M. Landmann, W.G. Schmidt, A. Gentils, J. Botsoa, and M.F. Barthe, Identification of the nitrogen split interstitial (N-N)N in GaN, Phys. Rev. Lett. 109, 206402 (2012), https://doi.org/10.1103 PhysRevLett.109.206402

[42]H.J. von Bardeleben, J.L. Cantin, H. Vrielinck, F. Callens, L. Binet, E. Rauls, and U. Gerstmann, Nitrogen split interstitial center $(\mathrm{N}-\mathrm{N}) \mathrm{N}$ in $\mathrm{GaN}$ : High frequency EPR and ENDOR study, Phys. Rev. B 90, 85203 (2014), https://doi.org/10.1103/ PhysRevB.90.085203

[43]R.Y. Korotkov, J.M. Gregie, and B.W. Wessels, Optical properties of the deep Mn acceptor in GaN:Mn, Appl. Phys. Lett. 80, 1731-1733 (2002), https://doi.org/10.1063/1.1456544

[44]A. Wolos, M. Palczewska, M. Zajac, J. Gosk, M. Kaminska, A. Twardowski, M. Bockowski, I. Grzegory, and S. Porowski, Optical and magnetic properties of $\mathrm{Mn}$ in bulk GaN, Phys. Rev. B 69, 115210 (2004), https://doi.org/10.1103 PhysRevB.69.115210

[45]Z. Zhang, A.R. Arehart, E.C.H. Kyle, J. Chen, E.X. Zhang, D.M. Fleetwood, R.D. Schrimpf, 
J.S. Speck, and S.A. Ringel, Proton irradiation effects on deep level states in Mg-doped p-type GaN grown by ammonia-based molecular beam epitaxy, Appl. Phys. Lett. 106, 022104 (2015), https://doi.org/10.1063/1.4905783

[46]S.J. Chung, O.H. Cha, H.K. Cho, M.S. Jeong, C-H. Hong, E.-K. Suh, and H.J. Lee, Photocurrent spectroscopy investigations of Mg-related defects levels in p-type GaN, MRS Proc. 595, F99W11.83 (1999), https://doi.org/10.1557/PROC-595F99W11.83

[47]G.C. Yi and B.W. Wessels, Deep level defects in Mg-doped GaN, MRS Proc. 423, 525-530 (1996), https://doi.org/10.1063/1.116075

[48]C.H. Qiu and J.I. Pankove, Deep levels and persistent photoconductivity in GaN thin films, Appl. Phys. Lett. 70, 1983-1985 (1997), https:// doi.org/10.1063/1.118799

[49]Z. Zhang, C.A. Hurni, A.R. Arehart, J. Yang, R.C. Myers, J.S. Speck, and S.A. Ringel, Deep traps in nonpolar m-plane $\mathrm{GaN}$ grown by ammonia-based molecular beam epitaxy, Appl. Phys. Lett. 100, 52114 (2012), https://doi. org/10.1063/1.3682528
[50]J.I. Pankove, Optical Processes in Semiconductors (Prentice-Hall, New Jersey, USA, 1971).

[51]R. Bhattacharya, B. Pal, and B. Bansal, On conversion of luminescence into absorption and the van Roosbroeck-Shockley relation, Appl. Phys. Lett. 100, 222103 (2012), https://doi. org/10.1063/1.4721495

[52]E. Gaubas, T. Ceponis, L. Deveikis, D. Dobrovolskas, V. Rumbauskas, and M. Viliunas, Roomtemperature infrared photoluminescence in GaN doped with various impurities, Opt. Mater. 94, 266-271 (2019), https://doi.org/10.1016/j.optmat.2019.05.054

[53]S. Sintonen, S. Kivisaari, S. Pimputkar, S. Suihkonen, T. Schulz, J.S. Speck, and S. Nakamura, Incorporation and effects of impurities in different growth zones within basic ammonothermal GaN, J. Cryth. Growth 456, 43-50 (2016), https:// doi.org/10.1016/j.jcrysgro.2016.08.040

[54]M. Julkarnain, N. Kamata, T. Fukuda, and Y. Arakawa, Yellow luminescence band in undoped GaN revealed by two-wavelength exited photoluminescence, Opt. Mater. 60, 481-486 (2016), https://doi.org/10.1016/j.optmat.2016.09.003

\title{
NEUTRONAIS APŠVITINTO AMONOTERMINĖS TECHNOLOGIJOS GaN SPEKTROSKOPIJA FOTOJONIZACIJOS, FOTOLIUMINESCENCIJOS IR POZITRONŲ ANIHILIACIJOS METODAIS
}

\author{
J. Pavlov ${ }^{\text {a }}$, T. Čeponis ${ }^{\text {a }}$, L. Deveikis ${ }^{\text {a }}$, T. Heikkinen ${ }^{\text {b, c }}$, J. Raisanen ${ }^{\text {c, }}$ V. Rumbauskas ${ }^{\text {a }}$, G. Tamulaitis ${ }^{\text {a }}$, \\ F. Tuomisto ${ }^{\text {b, }, d,}$, E. Gaubas ${ }^{a}$ \\ ${ }^{a}$ Vilniaus universiteto Fotonikos ir nanotechnologiju institutas, Vilnius, Lietuva \\ ${ }^{\mathrm{b}}$ Aalto universiteto Taikomosios fizikos fakultetas, Espas, Suomija \\ ${ }^{c}$ Helsinkio universiteto Fizikos fakultetas, Helsinkis, Suomija \\ ${ }^{\mathrm{d}}$ Helsinkio universiteto Fizikos institutas, Helsinkis, Suomija
}

\section{Santrauka}

Impulsinès fotojonizacijos, fotoliuminescencijos ir pozitronų anihiliacijos spektroskopinių tyrimų rezultatai buvo derinami siekiant identifikuoti savituosius ir radiacinius defektus reaktoriaus neutronais apšvitintose amonoterminès technologijos GaN (AT GaN) medžiagose, priemaišintose $\mathrm{Mn}$ ir Mg. Itvertintos defektų evoliucijos charakteristikos keičiant neutronų apšvitos ịtèkị plačiame $10^{12}-5 \times 10^{16} \mathrm{n} / \mathrm{cm}^{2}$ intervale. Atskleista, kad nespindulinę rekombinaciją nulemia galio vakansijos, kurių koncentracija yra didesnè Mn priemaišintame AT GaN. Vakansiju kompleksai su deguonies ir kitomis priemaišomis nulemia fotoliuminescencijos spektru evoliuciją ir visų aptiktų liuminescencijos smailių intensyvumo mažejjimą didejjant apšvitos ịtẻkiui. Fotojonizacijos ir fotoliuminescencijos spektrų sąsajos paaiškintos Kopylovo-Pikhtino ir van Roosbroeck'o-Shockley modelių artinyje. Vakansiniai defektai identifikuoti matuojant pozitronų gyvavimo trukmę. 